\title{
Low-dose IL-2 in children with recently diagnosed type 1 diabetes: a Phase I/II randomised, double-blind, placebo-controlled, dose-finding study
}

\author{
Michelle Rosenzwajg ${ }^{1,2}$ (D) Randa Salet ${ }^{3} \cdot$ Roberta Lorenzon $^{1,2} \cdot$ Nicolas Tchitchek $^{1,2} \cdot$ Alexandra Roux $^{1,2}$. \\ Claude Bernard $^{1,2}$. Jean-Claude Carel ${ }^{4} \cdot$ Caroline Storey $^{4} \cdot$ Michel Polak $^{5}$. Jacques Beltrand ${ }^{5} \cdot$ Chloé Amouyal $^{6}$. \\ Agnès Hartemann ${ }^{6}$. Pierre Corbeau ${ }^{7}$. Eric Vicaut ${ }^{8} \cdot$ Cecile Bibal $^{9} \cdot$ Pierre Bougnères $^{9} \cdot$ Tu-Anh Tran $^{3}$. \\ David Klatzmann ${ }^{1,2}$ (D)
}

Received: 2 October 2019 / Accepted: 6 May 2020 / Published online: 1 July 2020

(C) Springer-Verlag GmbH Germany, part of Springer Nature 2020

\begin{abstract}
Aims/hypothesis Low-dose IL-2 (ld-IL2) selectively activates and expands regulatory T cells (Tregs) and thus has the potential to skew the regulatory/effector $\mathrm{T}$ (Treg/Teff) cell balance towards improved regulation. We investigated which low doses of IL-2 would more effectively and safely activate Tregs during a 1 year treatment in children with recently diagnosed type 1 diabetes. Methods Dose Finding Study of IL-2 at Ultra-low Dose in Children With Recently Diagnosed Type 1 Diabetes (DF-IL2-Child) was a multicentre, double-blinded, placebo-controlled, dose-finding Phase I/II clinical trial conducted in four centres at university hospitals in France: 24 children (7-14 years old) with type 1 diabetes diagnosed within the previous 3 months were randomly assigned 1:1:1:1 to treatment by a centralised randomisation system, leading to a 7/5/6/6 patient distribution of placebo or IL-2 at doses of $0.125,0.250$ or 0.500 million international units (MIU) $/ \mathrm{m}^{2}$, given daily for a 5 day course and then fortnightly for 1 year. A study number was attributed to patients by an investigator unaware of the randomisation list and all participants as well as investigators and staff involved in the study conduct and analyses were blinded to treatments. The primary outcome was change in Tregs, expressed as a percentage of $\mathrm{CD}^{+} \mathrm{T}$ cells at day 5 . It pre-specified that a $\geq 60 \%$ increase in Tregs from baseline would identify Treg high responders.

Results There were no serious adverse events. Non-serious adverse events (NSAEs) were transient and mild to moderate. In treated patients vs placebo, the commonest NSAE was injection site reaction (37.9\% vs 3.4\%), whereas other NSAEs were at the
\end{abstract}

Michelle Rosenzwajg and Randa Salet contributed equally to this study.

Electronic supplementary material The online version of this article (https://doi.org/10.1007/s00125-020-05200-w) contains peer-reviewed but unedited supplementary material, which is available to authorised users.

David Klatzmann

david.klatzmann@sorbonne-universite.fr

1 Clinical Investigation Center for Biotherapies and Inflammation-Immunopathology-Biotherapy Department (i2B), AP-HP.Sorbonne Université, Pitié-Salpêtrière Hospital, 83 Bd de l'Hôpital, F-75013 Paris, France

2 UMR_S 959, Immunology-Immunopathology-Immunotherapy (i3), Sorbonne Université and Inserm, Paris, France

3 Department of Paediatrics, Nîmes University Hospital and Inserm U1183, Montpellier University, Montpellier, France

4 Department of Paediatric Endocrinology and Diabetology, and Centre de Référence des Pathologies Rares de l'Insulino-Sécrétion et de l'Insulino-Sensibilité, Robert-Debré Hospital, AP-HP Nord-Université de Paris Diderot \& UFR de Médecine Paris Diderot, Paris, France
Department of Paediatric Endocrinology, Gynecology and Diabetology, and Centre de Référence des Pathologies Rares de l'Insulino-Sécrétion et de l'Insulino-Sensibilité, Necker Enfants Malades Hospital, AP-HP.Centre \& Université de Paris, UFR de Médecine Paris Descartes, Paris, France

6 Department of Diabetology, Pitié-Salpêtrière Hospital, AP-HP. Sorbonne Université, Paris, France

7 Immunology Department, Nîmes University Hospital, Nîmes, France

8 Lariboisière Hospital, Clinical Trial Unit, AP-HP.Nord, Paris, France

9 Department of Paediatric Endocrinology, Bicêtre Hospital, AP-HP.Université Paris Saclay, Le Kremlin-Bicêtre, France 


\section{Research in context}

\section{What is already known about this subject?}

- Type 1 diabetes could benefit from low-dose IL-2 (Id-IL2) therapy because the disease is linked to abnormalities in the IL-2 pathway and regulatory T cells (Tregs)

- Proof-of-concept clinical trials have reported the safety and efficacy of Id-IL2 in autoimmune diseases, including type 1 diabetes

- The incidence of type 1 diabetes is increasing in children, so it is important to assess immunotherapies in this population and to define safe dosing

What is the key question?

- What is the optimal dose of IL-2 for safe expansion of Tregs during 1 year treatment of children with recently diagnosed type 1 diabetes?

What are the new findings?

- Id-IL2 in children was safe at all doses

- Treg low and high responders were identified; Treg high responders showed a better preservation of stimulated insulin secretion at 1 year compared with Treg low responders

- Baseline serum soluble IL-2 receptor $a$ and VEGF receptor 2 predicted the Treg response after the 5 day Id-IL2 course

How might this impact on clinical practice in the foreseeable future?

- These results support the investigation of chronic regimens of $0.5 \mathrm{MIU} \mathrm{m}^{-2}$ day-1 of IL-2, with a maximum of 1 $\mathrm{MIU} /$ day, to study the clinical benefit for children and adolescents with recently diagnosed type 1 diabetes in a fully powered efficacy study

same level (23.3\% vs 19.2\%). 1d-IL2 induced a dose-dependent increase in the mean proportion of Tregs, from $23.9 \%$ (95\% CI $-11.8,59.6)$ at the lowest to $77.2 \%(44.7,109.8)$ at the highest dose, which was significantly different from placebo for all dose groups. However, the individual Treg responses to IL-2 were variable and fluctuated over time. Seven patients, all among those treated with the 0.250 and $0.500 \mathrm{MIU} \mathrm{m}^{-2}$ day $^{-1}$ doses, were Treg high responders. At baseline, they had lower Treg proportions in $\mathrm{CD}^{+}$cells than Treg low responders, and serum soluble IL-2 receptor $\alpha$ (sIL-2RA) and vascular endothelial growth factor receptor 2 (VEGFR2) levels predicted the Treg response after the 5 day course. There was no significant change in glycaemic control in any of the dose groups compared with placebo. However, there was an improved maintenance of induced C-peptide production at 1 year in the seven Treg high responders as compared with low responders.

Conclusions/interpretation The safety profile at all doses, the dose-dependent effects on Tregs and the observed variability of the Treg response to ld-IL2 in children with newly diagnosed type 1 diabetes call for use of the highest dose in future developments. The better preservation of insulin production in Treg high responders supports the potential of Tregs in regulating autoimmunity in type 1 diabetes, and warrants pursuing the investigation of ld-IL2 for its treatment and prevention.

Trial registration ClinicalTrials.gov NCT01862120.

Funding Assistance Publique-Hôpitaux de Paris, Investissements d'Avenir programme (ANR-11-IDEX-0004-02, LabEx Transimmunom and ANR-16-RHUS-0001, RHU iMAP) and European Research Council Advanced Grant (FP7-IDEASERC-322856, TRiPoD).

Keywords Autoimmune diseases · Autoimmunity $\cdot$ Immunotherapy $\cdot$ T1D $\cdot$ Tolerance

$\begin{array}{llll}\text { Abbreviations } & & \text { iAUC } & \text { Incremental AUC } \\ \text { AP-HP } & \text { Assistance Publique-Hôpitaux de Paris } & \text { IDAA }_{1 \mathrm{c}} & \text { Insulin-dose-adjusted HbA } \mathrm{Hb}_{1 \mathrm{c}} \\ \text { DF-IL2-Child } & \begin{array}{l}\text { Dose Finding study of IL-2 at ultra-low } \\ \text { dose in Children with recently diagnosed }\end{array} & \text { IA2 } & \text { Islet antigen 2 } \\ & \text { ICA } 1 \text { diabetes } & \text { ld-IL2 } & \text { Islet cell antibodies } \\ \text { H-Treg } & \text { Treg high responder } & \text { ITT } & \text { Low-dose IL-2 } \\ & & & \text { Intention-to-treat }\end{array}$




$\begin{array}{ll}\text { L-Treg } & \text { Treg low responder } \\ \text { Treg } & \text { Regulatory T cell } \\ \text { MIU } & \text { Million international units } \\ \text { MMTT } & \text { Mixed meal tolerance test } \\ \text { NK } & \text { Natural killer } \\ \text { NSAE } & \text { Non-serious adverse event } \\ \text { sIL-2RA } & \text { Soluble IL-2 receptor } \alpha \\ \text { Teff } & \text { Effector T cell } \\ \text { TPO } & \text { Thyroperoxidase } \\ \text { VEGFR2 } & \text { Vascular endothelial growth factor } \\ & \text { receptor 2 } \\ \text { ZnT8 } & \text { Zinc transporter } 8\end{array}$

\section{Introduction}

Since the recognition that type 1 diabetes is an autoimmune disease, clinical trials have tested therapies to control or suppress islet autoimmunity. Trials began in the 1980s with the use of classical immunosuppressive agents, including cyclosporin, at the time of diagnosis. This efficiently controlled the autoimmune process, with some patients being insulin-free 2 years after diagnosis [1-4]. While these results further demonstrated the importance of autoimmunity in the pathogenesis of type 1 diabetes and provided proof of concept that immunotherapy could be effective, the drugs used had an unfavourable risk/benefit ratio [2]. Stem cell transplantation, by resetting the immune system, could also stop the autoimmune process, although with significant side effects and expense $[5,6]$.

The discovery that regulatory $\mathrm{T}$ cells (Tregs) control effector $\mathrm{T}$ cells (Teffs) has changed the paradigm from immune suppression to immune regulation to treat autoimmune diseases, including type 1 diabetes [7]. Attempts to stimulate antigen-specific Tregs with appropriate antigens to induce antigen-specific tolerance are being actively pursued [8,9], and so are Treg cell therapies [10]. The expansion and reinjection of large amounts of polyclonal Tregs have been shown to be safe, and to preserve C-peptide production in several individuals [11].

The recognition that IL-2, when given at low doses, can selectively stimulate Tregs has offered novel means for harnessing Tregs for type 1 diabetes treatment [12-17]. IL-2 is used at a high dose (18-60 million international units (MIU)/injection) as a marketed drug designed to stimulate Teffs for treating cancer [18]. Although IL-2 was the first effective immunotherapy for cancer, with $>5 \%$ long-duration complete response, the severe adverse effects of the drug at high doses precluded its large-scale use [19]. The recognition that, unlike other $\mathrm{T}$ cells, Tregs express constitutively the high-affinity receptor for IL-2 led us to hypothesise that low-dose IL-2 might preferentially activate Tregs over Teffs. We showed that this was indeed the case and that at low dose
(1.5-3 MIU/injection) IL-2 was well tolerated [20]. This opened the path to investigate low-dose IL-2 (ld-IL2) in type 1 diabetes, a disease which is associated with low IL-2 production and Treg insufficiency [21, 22]. We first conducted a dose-finding study in adult patients with established type 1 diabetes in order to determine a dose that would safely activate Tregs. A 5 day course of daily IL-2 injections led to a dose-dependent increase in Tregs over a dose range of 0.33 $3 \mathrm{MIU} /$ day. In another study, IL-2 was administered in combination with rapamycin with the aim of apoptosing diabetogenic Teffs [23]. Such treatment actually led to a Treg increase and to a transient decrease of C-peptide production [24], which has been attributed to the direct toxic effects of rapamycin on pancreatic beta cells [25].

As the treatment of type 1 diabetes with IL-2 is likely to be of long duration, we next aimed at investigating the lowest dose that would stimulate Tregs over a 1 year treatment. Type 1 diabetes is very commonly diagnosed in children, in whom disease progression and response to immunotherapies may differ from those of adult patients [26]. Therefore, we conducted a dose-finding study with ld-IL2 in children with recently diagnosed type 1 diabetes. Treating children with ldIL2 appeared possible because of the safety profile of the drug when given at low dose [12, 27]; moreover, even fetuses can be safely exposed to increased IL-2 concentrations during a normal pregnancy [28]. In adults we observed a good safety profile up to the dose of $3 \mathrm{MIU} /$ injection, but better tolerance at 1 MIU/injection [12]. The primary objective of the study was thus to determine the optimal dose of IL-2 for safe expansion of Tregs in children with recently diagnosed type 1 diabetes.

\section{Methods}

Study design and participants Dose Finding Study of IL-2 at Ultra-low Dose in Children With Recently Diagnosed Type 1 Diabetes (DF-IL2-Child) was a multicentre, randomised, double-blind, parallel-group study of three doses of IL-2 $\left(0.125,0.25\right.$ or $0.5 \mathrm{MIU} \mathrm{m}^{-2}$ day $\left.^{-1}\right)$. Patients were recruited, randomised, treated and followed up at three centres of the Assistance Publique-Hôpitaux de Paris (AP-HP) (KremlinBicêtre, Robert-Debré and Necker Hospitals) and one in Nîmes (Nîmes Hospital). Patients were eligible if they were aged 7-13 years for females or 7-14 years for males, and had a diagnosis of type 1 diabetes confirmed by the presence of at least one of the following diabetes-related autoantibodies: islet cell antibodies (ICA), GAD, islet antigen 2 (IA2) or zinc transporter protein 8 (ZnT8); had been treated with insulin for less than 3 months; had no history of or current cardiopathy; and had no clinically significant abnormal value in haematological, biochemical, hepatic and renal assessments, and had lymphocyte counts in the normal range. 
Exclusion criteria were a known contraindication to aldesleukin; a documented history of other autoimmune diseases (except stable thyroiditis); acidosis, $\mathrm{HbA}_{1 \mathrm{c}} \geq$ $119 \mathrm{mmol} / \mathrm{mol}(13 \%)$ and weight loss $\geq 10 \%$ at diagnosis; continuous nocturnal polyuria $\geq 3$ months; or positive autoantibodies to 21-hydroxylase or stage 2 obesity. Moreover, patients were not included if they had positive serology (IgM) indicating recent exposure to Epstein-Barr virus and/ or cytomegalovirus, or if they had received a vaccination with live attenuated virus in the previous 4 weeks. Immunomodulator, cytotoxic and plasma glucose-modifying drugs were not accepted during treatment (electronic supplementary material [ESM] Table 1).

The study was approved by the institutional review board of Pitié-Salpêtrière Hospital and was conducted in accordance with the Declaration of Helsinki and good clinical practice guidelines. Written, informed consent was obtained from all participants before enrolment in the study.

Dose, randomisation and masking As children aged 7-14 may vary considerably in size and weight, we adjusted the dose used per square metre, approximating that adults receiving $1 \mathrm{MIU} /$ injection have a body surface area of $1.8 \mathrm{~m}^{2}$. Patients were randomised in a 1:1:1:1 ratio to placebo or IL2 at one of the three targeted doses: $0.125,0.250$ or $0.500 \mathrm{MIU}$ $\mathrm{m}^{-2}$ day ${ }^{-1}$. Patients with a body surface area $\leq 1.1 \mathrm{~m}^{2}$ received $0.125,0.25$ or $0.5 \mathrm{MIU} /$ day and those with body surface area $>1.1 \mathrm{~m}^{2}$ received $0.2,0.4$ or $0.8 \mathrm{MIU} /$ day.

The randomisation list was generated by computer (block size of 4$)$, stratified by body surface area $\left(\leq 1.1 \mathrm{~m}^{2}\right.$ or $\left.>1.1 \mathrm{~m}^{2}\right)$ and forwarded to the pharmacist in charge of preparing the drug.

A study number was attributed to patients by an investigator unaware of the randomisation list, according to the patient's stratum of body surface area and order of entry in the centre. For each patient number and at each patient visit with drug administration, a pharmacist prepared the treatment according to the randomisation list, with labels bearing only the study number of the patient. Syringes containing placebo and IL-2 had the same appearance and were labelled according to good manufacturing practice for traceability and accountability purposes. All investigators remained blinded until the end of the study. The randomisation list was stored at the local pharmacy in each centre.

Procedures Aldesleukin (Proleukin 18 mIU, Novartis, Basel, Switzerland) was purchased by the Central Pharmacy of the AP-HP. For each patient, clinical trial units were prepared at the pharmacy of the centre. Syringes, each containing 0.5 (body surface area $\leq 1.1 \mathrm{~m}^{2}$ ) or $0.8 \mathrm{ml}$ (body surface area $>1.1 \mathrm{~m}^{2}$ ) of either a solution of aldesleukin at the required IL-2 dose $\left(0.125,0.25,0.50 \mathrm{MIU} / \mathrm{m}^{2}\right)$ or vehicle only (glucose $5 \%$ in water) used as placebo, were prepared according to the randomisation list. The experimental treatment was administered subcutaneously in a day-care ward or at home by a qualified nurse. The treatment was administered according to two periods: (1) an induction course of once daily administration for 5 days (day 1 to day 5); and (2) a maintenance course with fortnightly injections for 12 months (day 15 to day 337) (ESM Fig. 1). According to the study protocol, a 'prior single administration' was given at day minus 7 , followed by blood sampling at day minus 6 and day zero. This was done to measure the biological effects of a single injection at $24 \mathrm{~h}$ and 1 week post injection. The core treatment was then initiated and the monitoring of Tregs (primary outcome) performed at day 8 . Thus, the protocol called for eight visits within the first 15 days of the treatment and was not easy to implement because of poor acceptance by patients. To reduce patient burden, after the first five patients were recruited, the steering committee decided to remove this prior single administration and at the same time to switch the Treg evaluation for the primary outcome from day 8 to day 5 , just prior to the last treatment injection (ESM Fig. 1). These modifications were approved by the ethics committee and the regulatory agency.

Blood samples were obtained for specific immunological tests including assessment of Treg and lymphocyte subsets at day 1 (baseline), day $5 / 8$, day 15 , day 30 , day 45 , day 99 , day 183, day 267 and day 351, and for follow-up at day 436. Blood samples for assessment of diabetes variables (fasting blood glucose and C-peptide, $\mathrm{HbA}_{1 \mathrm{c}}$ ) were obtained on day 1 , day 99, day 183 , day 267 , day 351 and at day 436 of the follow-up; a mixed meal tolerance test (MMTT) was performed at day 1, day 183, day 351 and day 436. Routine laboratory assessments were (1) biochemistry, including blood glucose and blood electrolytes, lactate dehydrogenase, C-reactive protein, procalcitonin, blood calcium, and hepatic and renal functions; and (2) haematology, including haemoglobin, haematocrit, white blood cell count, erythrocyte count and platelets, and were performed at day 0 , day 15 , day 99, day 183, day 267, day 351 and day 436. Immunoglobulins and specific autoantibodies for thyroiditis (antithyroperoxidase [TPO] and anti-thyroid stimulating hormone [TSH] receptor), Addison's disease (anti-21 hydroxylase) and celiac disease (anti-transglutaminase) were evaluated at the screening visit and on day 183, day 351 and day 436 . Serology for cytomegalovirus and Epstein-Barr virus was evaluated at the screening visit and on day 99, day 183, day 267, day 351 and day 436.

The primary endpoint was the increase in the relative concentration of Tregs, measured by flow cytometry as $\mathrm{CD}^{+}{ }^{+} \mathrm{CD} 4{ }^{+} \mathrm{CD} 25^{\text {hi }} \mathrm{CD} 127^{-/ / \mathrm{lo}} \mathrm{FoxP} 3^{+}$cells among the $\mathrm{CD} 4^{+}$ $\mathrm{T}$ cells (ESM Fig. 2), at the end of the induction period compared with baseline. The baseline sample was obtained immediately prior to the first treatment administration (day 1). The post-treatment sample was obtained at day 5, except for the first five patients who received the prior single 
administration, and for whom it was performed at day 8 . The immunological secondary endpoint was the Treg response during the maintenance period compared with the baseline, expressed as the AUC of the changes from day 15 to day 351. All the immunomonitoring procedures (flow cytometry and quantification/analysis of cytokine and chemokine expression levels) are described in the ESM Methods.

Diabetes secondary endpoints were: change in C-peptide (fasting C-peptide and C-peptide AUC response to an MMTT), $\mathrm{HbA}_{1 \mathrm{c}}$ and insulin-dose-adjusted $\mathrm{HbA}_{1 \mathrm{c}}\left(\mathrm{IDAA}_{1 \mathrm{c}}\right.$ ) scores during the maintenance period compared with the baseline (ESM Table 2).

Safety was assessed with vital signs (temperature, weight, blood pressure, heart rate); adverse events were reported at each visit, with a systematic assessment of the most commonly reported reactions to IL-2 during hospital visits at day 1 to day 5 , day 15 , day 99 , day 183 , day 267 , day 351 and day 436 . Adverse events were graded according to the WHO Common Toxicity Criteria (version 3.0). A safety committee of five independent experts was established to review all serious adverse events. Records of insulin intake and of hypoglycaemic episodes during the treatment period were recorded by the patients and collected during visits.

Statistical analysis Power calculations [29] determined that six patients per arm would provide $80 \%$ power in detecting a difference between active drug and placebo, corresponding to an effect size equal to 1.8 for the main criterion of the study. Such an effect size has been anticipated using data from a previous study [20].

All outcomes were analysed in the intention-to-treat (ITT) population with the exception of variables linked to the MMTT, since some patients exhibited major deviations in this test that prevented interpretation of their exams (ESM Table 3).

Since the main objective of the study was to identify the lowest dose of IL-2 active on Tregs, we analysed the doseresponse relationship for the main criterion by the Jonckheere-Terpstra test and compared each dose vs placebo by the non-parametric Shirley-Williams test.

A similar method was used to compare groups for AUC during the maintenance phase. In addition, we compared the time-dependent profile of changes in Tregs during the maintenance phase by ANOVA on ranks and tested the significance of the increase in Tregs during the maintenance phase by calculating the AUC of the difference of each time from baseline, and testing that this difference was significantly different from zero. According to their statistical distributions, quantitative secondary criteria were compared among the four groups by ANOVA (after log-transformation if required) or the Kruskal-Wallis test and between high and low responders by the $t$ test (after log-transformation if required) or MannWhitney test. Numbers of episodes of hypo/hyperglycaemia were compared using generalised estimating equations for Poisson regression.

Role of the funding source The sponsor of the study had no role in study design. M. Rosenzwajg, R. Lorenzon, C. Bernard, E. Vicaut and D. Klatzmann had access to the raw data. The corresponding author had full access to all the data in the study and had final responsibility for the decision to submit for publication.

\section{Results}

Patients were enrolled between June 2013 and January 2016 (Fig. 1). Twenty-four patients were randomised, leading to a $7 / 5 / 6 / 6$ patient distribution for the $0,0.125,0.25$ and $0.5 \mathrm{IL}-2$ doses, respectively. One patient, in the $0.5 \mathrm{MIU} / \mathrm{m}^{2}$ group, dropped out of the study after 270 days because of grade 2 abdominal pain (Fig. 1). No major deviations were observed during the study. Minor protocol deviations included out-ofwindow visits $(n=110 / 576 ; 19 \%)$ or drug administration not performed because of intercurrent diseases $(n=2)$ during the maintenance period. Some deviations in the MMTT have been reported (ESM Table 3). Diabetes secondary outcomes were analysed in the ITT population and in the per-protocol population, which excluded patients with major deviations in the MMTT.

There was no difference between groups at baseline for demographic and laboratory characteristics, including diabetes variables (fasting blood glucose level, fasting C-peptide and C-peptide AUC) (Table 1), or for biological/ immunological variables, including Tregs (Fig. 2a). According to the inclusion criteria, all patients had at least one positive type 1 diabetes-associated autoantibody. AntiGAD and anti-IA2 antibodies were the most frequent such autoantibodies, in accordance with the literature.

Safety Clinical safety was satisfactory at all doses; no serious adverse events occurred during the treatment and offtreatment follow-up periods (Table 2). Over the entire observation period, non-serious adverse events (NSAEs) were all transient and mild to moderate. During the treatment period, there was a dose-effect relationship for all NSAEs taken together. Local reactions at the injection site accounted for most of the common NSAEs, from $3.4 \%$ of administrations for placebo-treated patients to $37.9 \%$ for ld-IL2-treated patients, with a dose-effect relationship corresponding to $26.2 \%, 36.9 \%$ and $47.7 \%$ at the $0.125,0.25$ and $0.5 \mathrm{MIU}$ $\mathrm{m}^{-2}$ day $^{-1}$ doses, respectively. The other NSAEs (headache, gastrointestinal symptoms, transient asthenia and fever) had the same frequency in the different therapy groups (23.3\%) and placebo (19.2\%). Importantly, the 1 year treatment period covered the seasons with a high rate of infections. Four upper 


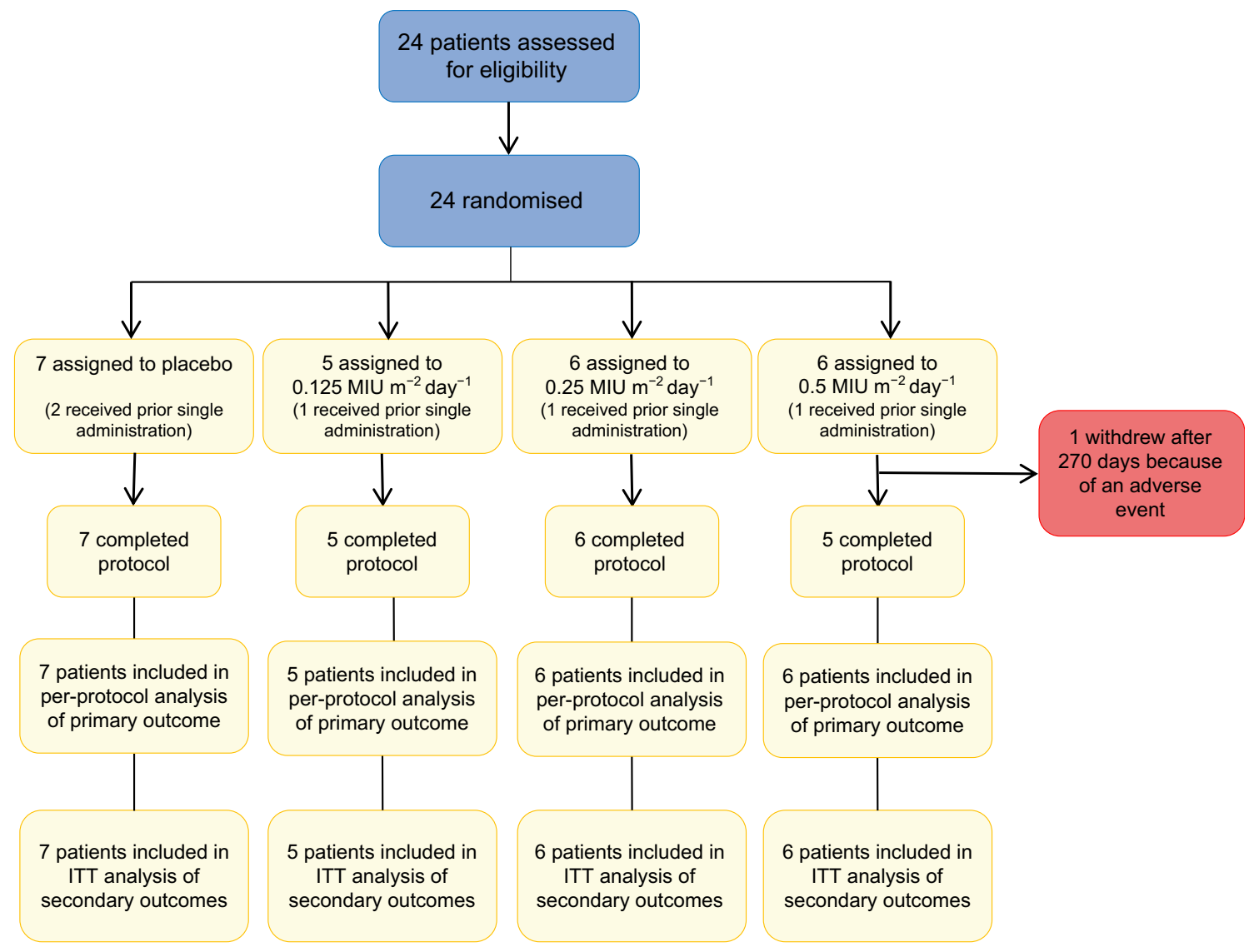

Fig. 1 Trial profile. Twenty-four patients were assessed for eligibility and randomised. Seven were assigned to placebo, five to $0.125 \mathrm{MIU}$ $\mathrm{m}^{-2}$ day $^{-1}$, six to $0.25 \mathrm{MIU} \mathrm{m}^{-2}$ day $^{-1}$ and six to $0.5 \mathrm{MIU} \mathrm{m}^{-2}$ day $^{-1}$. In the initial version of the protocol, the first five patients (two placebo and one for each dose) received a prior single administration of IL-2 1 week before the induction course and their Treg response was measured

respiratory tract infections were noted and all resolved rapidly without complications (Table 2).

Two patients had hypereosinophilia during the maintenance period, but no concomitant allergic disease or other symptoms related to hypereosinophilia were observed (ESM Fig. 3). One patient had anti-TPO antibodies at baseline that doubled at month 6 , with normal thyroid function throughout the treatment and follow-up periods. No adverse events were reported concerning other laboratory variables.

\section{Primary efficacy criteria: IL-2 effects on Tregs during the} induction course The mean $(95 \% \mathrm{CI})$ baseline percentage of Tregs in patients was $5.5 \%(5.0,6.1)$ of $\mathrm{CD}^{+} \mathrm{T}$ cells (Table 1 and Fig. 2a). At the end of the induction period, a significant dose-response relationship between Treg increase and IL-2 dose $(p=0.0002)$ was observed as the primary efficacy endpoint. The mean relative change in Tregs was $-0.2 \%$ $(-30.4,30.0)$ in the placebo group and $23.9 \%(-11.8,59.6)$ $(p=0.02), 54.2 \%(21.6,86.8)(p=0.007)$ and $77.2 \%(44.7$, $109.8)(p=0.0002)$ for the $0.125,0.25$ and $0.5 \mathrm{MIU}$ $\mathrm{m}^{-2}$ day ${ }^{-1}$ doses, respectively (Fig. 2b, c and ESM Table 4). at day 8. In a modified version of the protocol aimed at facilitating recruitment, this single injection was eliminated and Tregs were determined at day 5 just prior to the IL-2 injection. One patient dropped out of the study at day 270 because of grade 2 abdominal pain. All patients were analysed for primary and secondary endpoints

Although mean Treg values were significantly different from those of placebo at all IL-2 doses, the individual Treg response to IL-2 appeared variable.

As pre-specified in the protocol, an individual was defined as a Treg high responder (an H-Treg patient) if his/her Treg response showed a $\geq 60 \%$ increase over baseline at day 5 . According to this criterion, seven patients were H-Treg, three and four of whom received the 0.250 and $0.500 \mathrm{MIU}$ $\mathrm{m}^{-2}$ day ${ }^{-1}$ doses, respectively (Fig. 2b). The other patients had a low Treg response (Treg low responders [L-Treg patients]) (Fig. 2b). This heterogeneity of the Treg response to IL-2 was reminiscent of what we observed in our previous trial in adults with established type 1 diabetes (Fig. 3) [12].

Immunological secondary efficacy criteria Time-dependent changes in Tregs during the maintenance course differed between groups. While the mean Treg values rapidly returned to baseline after the induction course for patients receiving the lowest dose, they remained elevated over the baseline during the entire maintenance course for the two highest doses, with a significant effect only for the highest $(p=0.02$ for $0.5 \mathrm{MIU}$ 
Table 1 Baseline demographic and laboratory characteristics of patients (ITT population): data are mean \pm SD, number of patients $(n)$ or $\%(n)$

\begin{tabular}{|c|c|c|c|c|c|c|c|c|}
\hline Characteristic & $\begin{array}{l}\text { Placebo } \\
(n=7)\end{array}$ & $\begin{array}{l}0.125 \mathrm{MIU} / \mathrm{m}^{2} \\
(n=5)\end{array}$ & $\begin{array}{l}0.25 \mathrm{MIU} / \mathrm{m}^{2} \\
(n=6)\end{array}$ & $\begin{array}{l}0.5 \mathrm{MIU} / \mathrm{m}^{2} \\
(n=6)\end{array}$ & $p$ value & $\begin{array}{l}\text { L-Treg } \\
(n=17)\end{array}$ & $\begin{array}{l}\text { H-Treg } \\
(n=7)\end{array}$ & $p$ value \\
\hline \multicolumn{9}{|l|}{ Demographics } \\
\hline Sex (male/female) & $5 / 2$ & $1 / 4$ & $2 / 4$ & $4 / 2$ & $0.2748^{\mathrm{a}}$ & $8 / 9$ & $4 / 3$ & $1.000^{\mathrm{a}}$ \\
\hline Age (years) & $9.3 \pm 1.4$ & $10.6 \pm 1.1$ & $9.7 \pm 1.6$ & $10.2 \pm 2$ & $0.4985^{\mathrm{b}}$ & $10 \pm 1.6$ & $9.6 \pm 1.6$ & $0.5586^{\mathrm{c}}$ \\
\hline BMI $\left(\mathrm{kg} / \mathrm{m}^{2}\right)$ & $16.4 \pm 2$ & $19.4 \pm 2.9$ & $16.5 \pm 1.8$ & $18.2 \pm 2.3$ & $0.1100^{\mathrm{d}}$ & $17.7 \pm 2.4$ & $17.1 \pm 2.6$ & $0.6176^{\mathrm{e}}$ \\
\hline $\operatorname{BSA}\left(\mathrm{m}^{2}\right)$ & $1.2 \pm 0.2$ & $1.3 \pm 0.2$ & $1.2 \pm 0.3$ & $1.2 \pm 0.3$ & $0.8574^{\mathrm{d}}$ & $1.2 \pm 0.2$ & $1.1 \pm 0.2$ & $0.1614^{\mathrm{e}}$ \\
\hline $\mathrm{BSA}>1.1 \mathrm{~m}^{2}, \%(n)$ & $57.1 \%(4)$ & $80 \%(4)$ & $50 \%(3)$ & $66.7 \%(4)$ & $0.8434^{\mathrm{a}}$ & $64.7 \%(11)$ & $57.1 \%(4)$ & $1.0000^{\mathrm{a}}$ \\
\hline $\mathrm{BSA} \leq 1.1 \mathrm{~m}^{2}, \%(n)$ & $42.9 \%(3)$ & $20 \%(1)$ & $50 \%(3)$ & $33.3 \%(2)$ & & $35.3 \%(6)$ & $42.9 \%(3)$ & \\
\hline \multicolumn{9}{|l|}{ Glucose metabolism } \\
\hline Daily insulin dose $\left(\mathrm{U} \mathrm{kg}^{-1}\right.$ day $\left.^{-1}\right)$ & $0.5 \pm 0.3$ & $0.5 \pm 0.1$ & $0.3 \pm 0.2$ & $0.6 \pm 0.5$ & $0.5267^{\mathrm{d}}$ & $0.5 \pm 0.2$ & $0.4 \pm 0.4$ & $0.7669^{\mathrm{e}}$ \\
\hline Fasting blood glucose (mmol/l) & $5.6 \pm 1.6$ & $5.7 \pm 0.7$ & $5.5 \pm 1.2$ & $5.8 \pm 1.8$ & $0.9796^{\mathrm{d}}$ & $5.7 \pm 1.4$ & $5.5 \pm 1.1$ & $0.6498^{\mathrm{e}}$ \\
\hline Fasting C-peptide (nmol/1) & $0.23 \pm 0.10$ & $0.33 \pm 0.07$ & $0.30 \pm 0.10$ & $0.33 \pm 0.13$ & $0.2668^{\mathrm{d}}$ & $0.30 \pm 0.13$ & $0.30 \pm 0.10$ & $0.9986^{\mathrm{e}}$ \\
\hline C-peptide AUC $(\mathrm{nmol} / 1 \times \mathrm{h})$ & $0.96 \pm 0.49$ & $1.23 \pm 0.13$ & $1.13 \pm 0.49$ & $1.19 \pm 0.56$ & $0.7810^{\mathrm{d}}$ & $1.13 \pm 0.46$ & $1.13 \pm 0.43$ & $0.9332^{\mathrm{e}}$ \\
\hline $\mathrm{HbA}_{1 \mathrm{C}}(\mathrm{mmol} / \mathrm{mol})$ & $61.6 \pm 14.6$ & $50.6 \pm 3.5$ & $64.7 \pm 21.3$ & $57.4 \pm 9.2$ & $0.1794^{\mathrm{b}}$ & $58.0 \pm 10.8$ & $61.4 \pm 21.2$ & $0.6558^{\mathrm{c}}$ \\
\hline$(\%)$ & $(7.8 \pm 1.3)$ & $(6.8 \pm 0.3)$ & $(8.1 \pm 1.9)$ & $(7.4 \pm 0.8)$ & & $(7.5 \pm 1.0)$ & $(7.8 \pm 1.9)$ & \\
\hline $\mathrm{IDAA}_{1 \mathrm{c}}$ & $9.8 \pm 1.2$ & $8.9 \pm 0.7$ & $9.3 \pm 2.5$ & $9.5 \pm 2.5$ & $0.5934^{\mathrm{b}}$ & $9.4 \pm 1.1$ & $9.6 \pm 2.9$ & $0.2703^{\mathrm{c}}$ \\
\hline \multicolumn{9}{|l|}{ Autoantibodies (positive/patients tested) } \\
\hline ICA & $3 / 3$ & $1 / 3$ & $0 / 2$ & $2 / 3$ & $0.4728^{\mathrm{a}}$ & $4 / 9$ & $2 / 2$ & $0.4030^{\mathrm{a}}$ \\
\hline IAA & $1 / 3$ & $1 / 4$ & $1 / 4$ & $1 / 5$ & $0.8946^{\mathrm{a}}$ & $4 / 11$ & $0 / 5$ & $0.3687^{\mathrm{a}}$ \\
\hline GAD & $5 / 7$ & $3 / 5$ & $6 / 6$ & $4 / 6$ & $0.5070^{\mathrm{a}}$ & $13 / 17$ & $5 / 7$ & $1.0000^{\mathrm{a}}$ \\
\hline IA 2 & $6 / 7$ & $3 / 5$ & $5 / 6$ & $3 / 6$ & $0.5161^{\mathrm{a}}$ & $13 / 17$ & $4 / 7$ & $0.3742^{\mathrm{a}}$ \\
\hline ZnT8 & $1 / 2$ & $0 / 0$ & $0 / 1$ & $0 / 1$ & $1.000^{\mathrm{a}}$ & $1 / 2$ & $0 / 2$ & $0.4401^{\mathrm{a}}$ \\
\hline \multicolumn{9}{|l|}{ Immunocytometry } \\
\hline Tregs $\left(\%\right.$ of $\mathrm{CD} 4^{+} \mathrm{T}$ cells $)$ & $6.4 \pm 1.1$ & $5.8 \pm 0.9$ & $4.9 \pm 1.9$ & $4.9 \pm 0.7$ & $0.1232^{\mathrm{d}}$ & $6.1 \pm 1.1$ & $4.3 \pm 1.0$ & 0.0018 \\
\hline $\mathrm{CD}^{+} \mathrm{T}$ cells $\left(\right.$ cells per $\mathrm{mm}^{3}$ ) & $778 \pm 146$ & $931 \pm 271$ & $1133 \pm 427$ & $731 \pm 190$ & $0.0977^{\mathrm{d}}$ & $884 \pm 309$ & $877 \pm 299$ & 0.9607 \\
\hline $\mathrm{CD}^{+} \mathrm{T}$ cells $\left(\right.$ cells per $\mathrm{mm}^{3}$ ) & $500 \pm 194$ & $522 \pm 123$ & $738 \pm 339$ & $542 \pm 296$ & $0.3610^{\mathrm{d}}$ & $556 \pm 256$ & $620 \pm 274$ & 0.5894 \\
\hline $\mathrm{CD} 19^{+} \mathrm{B}$ cells (cells per $\mathrm{mm}^{3}$ ) & $357 \pm 116$ & $320 \pm 131$ & $344 \pm 174$ & $268 \pm 151$ & $0.7132^{\mathrm{d}}$ & $328 \pm 138$ & $314 \pm 151$ & 0.8244 \\
\hline $\mathrm{CD} 6^{+} \mathrm{CD} 3^{-} \mathrm{NK}$ cells $\left(\right.$ cells per $\mathrm{mm}^{3}$ ) & $149 \pm 146$ & $99 \pm 59$ & $127 \pm 86$ & $99 \pm 68$ & $0.8141^{\mathrm{b}}$ & $116 \pm 106$ & $131 \pm 75$ & 0.3248 \\
\hline
\end{tabular}

${ }^{\text {a }}$ Fisher's exact test

${ }^{\mathrm{b}}$ Kruskal-Wallis test

${ }^{\mathrm{c}}$ Mann-Whitney $U$ test/Wilcoxon rank-sum test

d ANOVA

e Two-sample $t$ test

BSA, body surface area; IAA, insulin autoantibodies

$\mathrm{m}^{-2}$ day $^{-1}$ ) (Fig. 2c and ESM Tables 4, 5). The increased percentage of $\mathrm{CD} 4^{+}$Tregs was associated with an increase in the Treg/Teff ratio (Fig. 2d). There were no statistically significant changes during induction and maintenance periods in activated CD25 ${ }^{+}$Teffs (ESM Fig. 4), B cells or natural killer (NK) cells (ESM Fig. 5) in any of the dose groups.

As a mean, the $\mathrm{H}$-Treg patients maintained a 50\% increase of Tregs throughout the treatment period (Fig. 4b). However, there were individual variations (Fig. 4c) that we did not see in other clinical trials of ld-IL2 [12, 27]. In contrast, the L-Treg patients had Treg values that never exceeded the threshold of a $60 \%$ increase. As a mean, L-Treg patients (treated with IL-2 or placebo) maintained Treg levels around baseline values (Fig. 4d).
Metabolic secondary efficacy criteria We found no deleterious effects of ld-IL2 on blood glucose levels. In the ITT population, there was no significant difference between the four treatment groups in any variables including plasma C-peptide incremental AUC (iAUC) response during an MMTT, $\mathrm{HbA}_{1 \mathrm{c}}$, fasting blood glucose levels, fasting C-peptide levels and insulin requirements (Fig. 2e, ESM Fig. 6 \& ESM Table 2).

There were, however, differences between $\mathrm{H}$-Treg and LTreg patients in plasma C-peptide iAUC response during an MMTT. Both groups showed an initial similar decrease from baseline to month 6 , after which the $\mathrm{C}$-peptide remained stable in the H-Treg group, whereas it decreased further in L-Treg 


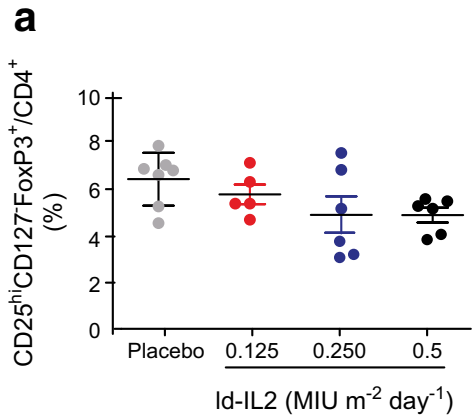

b

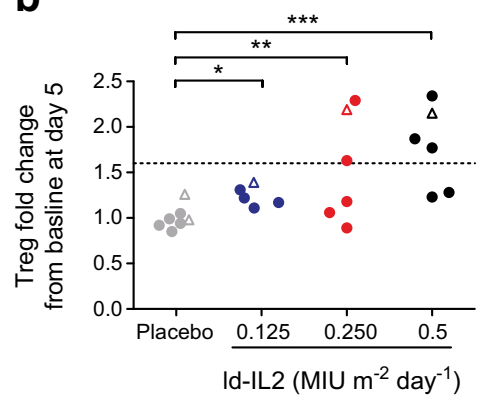

C

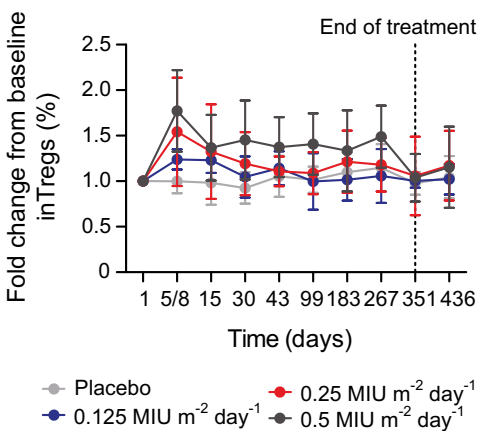

d

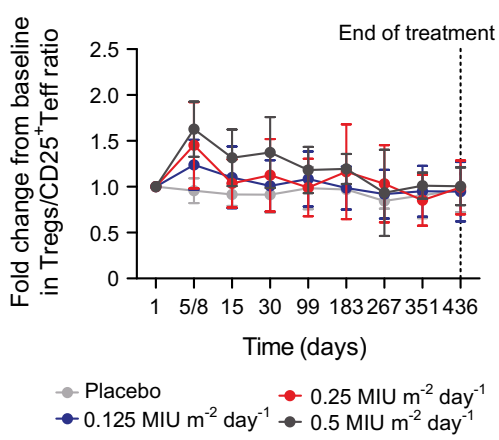

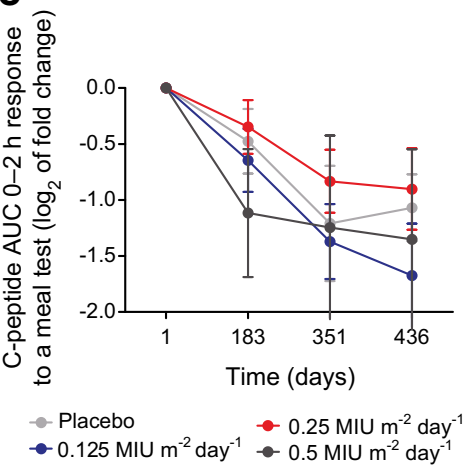

Fig. 2 Treg and C-peptide dynamics in patients treated with ld-IL2. (a) Data represent Tregs as a percentage of $\mathrm{CD}^{+} \mathrm{T}$ cells in the different groups of patients at baseline. (b) Representation of the primary outcome: individual change in Tregs at day 5 (dots) or day 8 (triangles) compared with baseline per IL-2 dose. (c) Secondary outcome: mean \pm SEM changes in Tregs over the whole treatment period and follow-up per IL-2 dose. (d) Data represent changes in Treg/Teff ratio defined as the percentage of

patients. At days 351 and 436, changes from baseline were significant for L-Treg patients $(p<0.001)$, but not for $\mathrm{H}$-Treg patients. No difference in $\mathrm{HbA}_{1 \mathrm{c}}$ and $\mathrm{IDAA}_{1 \mathrm{c}}$ scores was observed (ESM Table 2).

\section{Identification of potential biomarkers of patients' responses}

We first looked at Treg levels at baseline. H-Treg patients had a lower level of Tregs compared with L-Treg patients (4.3 \pm 1.0 vs $6.1 \pm 1.1, p=0.018$ ) (Fig. $4 \mathrm{a}$ ). There were no differences between the H- and L-Treg groups in Teffs, B cells or NK cells.

We then analysed whether the expression levels of 61 serum cytokines/chemokines at baseline were correlated with Treg increase at day 5 relative to baseline. We found a positive correlation between soluble IL-2 receptor $\alpha$ (sIL-2RA) ( $p=$ $0.0004)$, vascular endothelial growth factor receptor 2 (VEGFR2) $(p=0.0063)$, IL-22 $(p=0.0207)$, IL-27 $(p=$ $0.0137)$ and IL-28A $(p=0.0183)$ (Fig. 5a-e). However, at baseline, sIL-2RA and VEGFR2 were the only cytokines statistically differentially expressed between $\mathrm{H}$ - and L-Treg patients ( $p=0.0202$ and $p=0.0211$, respectively) (Fig. 5f, g).

To evaluate the potential of these biomarkers to predict the Treg response, we constructed a regression model using the
Tregs divided by the percentage of $\mathrm{CD}^{+} \mathrm{CD} 25^{1 \mathrm{lo} / 4} \mathrm{FoxP} 3^{-} \mathrm{T}$ cells; mean \pm SEM changes in Treg/Teff ratio over the whole treatment period and follow-up per IL-2 dose. (e) Changes in C-peptide AUC from baseline to day 436 per IL-2 dose. Data were normalised by baseline values for each patient at the different time points and are represented as mean fold change \pm SEM, but all statistics were calculated using the raw data

multivariate adaptive regression spline method [30] (Fig. 5h, i). The generated model was able to correctly predict the percentage of Tregs at day 5 relative to baseline (Pearson coefficient of correlation $=0.84$ and $p=2.078 \times 10^{-07}$ ). The expression levels of sIL-2RA and VEGFR2 were the only contributors to this regression model. The generalised crossvalidation coefficient used to estimate the importance of each variable in the model showed a dominant importance of sIL2Ra compared with VEGFR2. sIL-2RA does not have any clear biological function and is viewed as a surrogate marker of Treg activation [27]. In addition, polymorphism of sIL2RA and VEGFR2 have been described in type 1 diabetes [31] and other autoimmune diseases [32-34]. Altogether, this warrants further evaluation of these markers in future studies.

\section{Discussion}

Immunotherapy holds great promise in the treatment of autoimmunity in type 1 diabetes. An extreme modality is allogeneic haematopoietic stem cell transplantation, which has been reported to induce long-term complete remission (insulin independence) in patients with recently diagnosed type 1 
Table 2 Summary of adverse events (ITT population)

\begin{tabular}{|c|c|c|c|c|c|c|}
\hline Variable & $\begin{array}{l}\text { Placebo } \\
(n=7)\end{array}$ & $\begin{array}{l}0.125 \mathrm{MIU} / \mathrm{m}^{2} \\
(n=5)\end{array}$ & $\begin{array}{l}0.25 \mathrm{MIU} / \mathrm{m}^{2} \\
(n=6)\end{array}$ & $\begin{array}{l}0.5 \mathrm{MIU} / \mathrm{m}^{2} \\
(n=6)\end{array}$ & $\begin{array}{l}\text { L-Treg } \\
(n=17)\end{array}$ & $\begin{array}{l}\text { H-Treg } \\
(n=7)\end{array}$ \\
\hline Number of treatments administered (per 29 patients) & 203 & 145 & 174 & 174 & 493 & 203 \\
\hline Induction (per 5 patients) & 35 & 25 & 30 & 30 & 85 & 35 \\
\hline Maintenance (per 24 patients) & 168 & 120 & 144 & 144 & 408 & 168 \\
\hline Serious adverse events & 0 & 0 & 0 & 0 & 0 & 0 \\
\hline NSAEs & 46 & 76 & 102 & 124 & 211 & 137 \\
\hline$\%$ administrations & $22.7 \%$ & $52.4 \%$ & $58.6 \%$ & $71.3 \%$ & $42.8 \%$ & $67.5 \%$ \\
\hline Injection site reaction & 7 & 38 & 66 & 83 & 108 & 86 \\
\hline Number of patients & 4 & 4 & 5 & 6 & 12 & 7 \\
\hline$\%$ administrations & $3.4 \%$ & $26.2 \%$ & $36.9 \%$ & $47.7 \%$ & $21.9 \%$ & $42.4 \%$ \\
\hline Induction period & 3 & 7 & 8 & 20 & 17 & 21 \\
\hline Number of patients & 1 & 3 & 3 & 5 & 6 & 6 \\
\hline$\%$ administrations & $8.6 \%$ & $28.0 \%$ & $26.7 \%$ & $66.7 \%$ & $20.0 \%$ & $60.0 \%$ \\
\hline Maintenance period & 4 & 31 & 58 & 63 & 91 & 65 \\
\hline Number of patients & 3 & 4 & 6 & 6 & 11 & 8 \\
\hline$\%$ administrations & $2.4 \%$ & $25.8 \%$ & $40.3 \%$ & $43.8 \%$ & $22.3 \%$ & $38.7 \%$ \\
\hline Other NSAEs & 39 & 38 & 36 & 41 & 103 & 51 \\
\hline Number of patients & 7 & 5 & 6 & 6 & 17 & 7 \\
\hline$\%$ administrations & $19.2 \%$ & $26.2 \%$ & $20.7 \%$ & $23.6 \%$ & $20.9 \%$ & $25.1 \%$ \\
\hline Other NSAEs related to treatment & 2 & 8 & 2 & 11 & 13 & 10 \\
\hline Number of patients & 1 & 5 & 2 & 6 & 8 & 6 \\
\hline$\%$ administrations & $1.0 \%$ & $5.5 \%$ & $1.1 \%$ & $6.3 \%$ & $2.6 \%$ & $4.9 \%$ \\
\hline Headache & 2 & 3 & 1 & 2 & 6 & 2 \\
\hline Gastrointestinal symptoms & 0 & 3 & 0 & 4 & 2 & 5 \\
\hline Asthenia & 0 & 1 & 0 & 2 & 1 & 2 \\
\hline Upper respiratory tract infections & 0 & 1 & 1 & 2 & 3 & 1 \\
\hline Fever & 0 & 0 & 0 & 1 & 1 & 0 \\
\hline
\end{tabular}

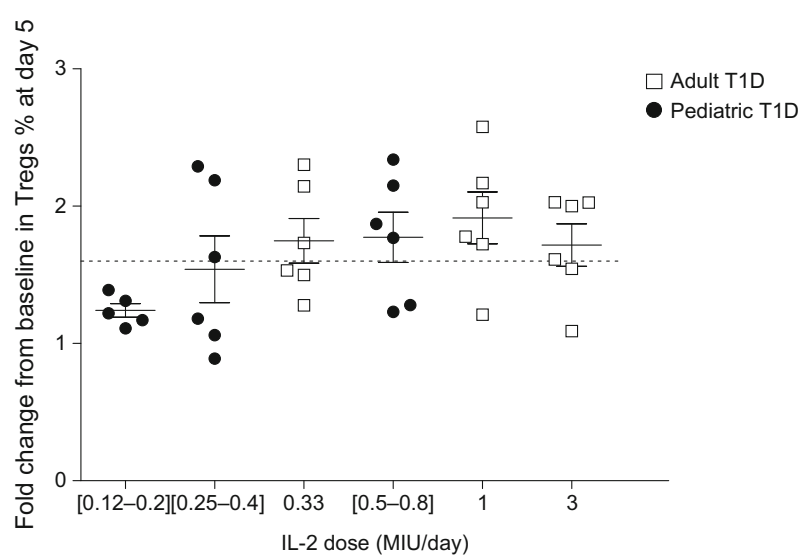

Fig. 3 Comparison of the Treg increase per IL-2 dose in newly diagnosed paediatric type 1 diabetes (DF-IL2-Child trial) and in adults with established type 1 diabetes (DF-IL2 trial [12]). Representation of individual changes in Tregs after the induction period compared with baseline per IL-2 dose in DF-IL2-Child (black dots) and in DF-IL2 (white squares). Values on the $x$-axis include dose ranges for DF-IL2-Child, which differed from the doses used in DF-IL2. Data were normalised by baseline values for each patient at the different time points and are represented as mean fold change $\pm \mathrm{SEM}$, but all statistics were calculated using the raw data. T1D, type 1 diabetes diabetes [35]. However, as for the use of cyclosporin, its side effects do not allow its broad use. Targeting the regulatory arm of the immune response may offer efficacious and safer means to treat type 1 diabetes. Results from our trial emphasise the safety profile of ld-IL2 in type 1 diabetes in children 7-14 years old. The main adverse event was a reaction at the injection site; the frequency was dose-related, but reactions were mild to moderate and did not require medication. Since the treatment lasted for 1 year, all patients went through the cold months in which infections are more prevalent. There were very few infectious episodes reported and all showed a normal course. These results add to the expanding clinical experience showing a very good safety profile of ld-IL2.

As this trial was a dose-finding one, the main primary outcome was the Treg response after the five daily consecutive IL-2 injections. In our previous trial in adults with established type 1 diabetes, we reported at the same time point a dose-dependent and significant increase in Tregs at all doses (3, 1 and $0.33 \mathrm{MIU} /$ injection). Due to the large variation in body surface area in children, we adapted our injected dose of 

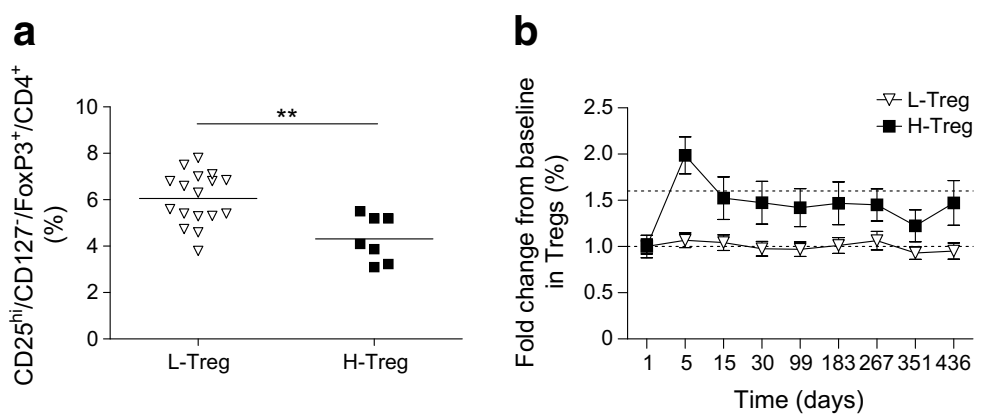

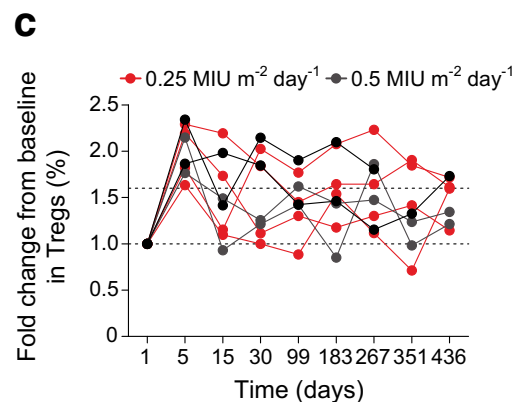

Fig. 4 Treg and C-peptide dynamics in L-Treg and H-Treg patients. (a) Data represent mean Tregs as a percentage of $\mathrm{CD}^{+} \mathrm{T}$ cells in L-Treg and $\mathrm{H}$-Treg patients at baseline. (b-d) Changes in Tregs over the whole treatment period and follow-up from day 1 to day 436 in L-Treg and H-Treg patients. Lower dashed line represents baseline level of Tregs and upper dashed line represents the primary outcome with $a \geq 60 \%$ increase in

IL-2 according to this variable, approximating the body surface area of adults to around $1.8 \mathrm{~m}^{2}$. In line with our previous results, we observed a dose-dependent increase of Tregs that was significant at all doses, including the lowest dose of $0.125 \mathrm{MIU} / \mathrm{m}^{2}$. We had noticed some variability in the Treg response in our trial in adults, with some patients receiving the highest dose who responded less than others receiving the lowest dose. We had thus pre-specified the threshold of a $\geq 60 \%$ increase in Tregs to define a robust response to IL-2. According to this criterion, no patient had such a response at the lowest dose, while 3/6 and 4/6 had it in the two highestdose groups; thus, $58 \%$ of the type 1 diabetic children treated with the two highest doses had a high Treg response. For reference, we had 35/46 (76\%) high responders in our TRANSREG trial of adult patients with one of 11 autoimmune diseases receiving $1 \mathrm{MIU} /$ injection [27]. It is noteworthy that, at baseline, the H-Treg responders had a lower proportion of peripheral blood Tregs than L-Treg responders, and also had higher plasma sIL-2RA levels, which are known to reflect Treg activation [16, 36, 37]. These observations suggest that $\mathrm{H}$-Treg responders have actively engaged Tregs that may not be receiving the amount of IL-2 they need for optimal efficacy. This is further supported by the capacity to predict the Treg response based on plasma sIL-2RA levels at baseline. Altogether, the dose of $1 \mathrm{MIU} /$ injection, adjusted to body surface area in the case of children, appears to be optimal regarding our administration scheme. Indeed, it is safe and the

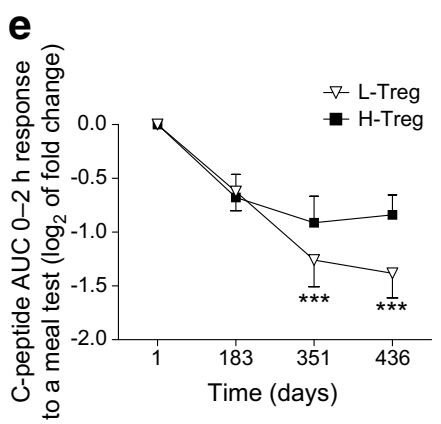

Tregs from baseline. (b) Mean \pm SEM in L-Treg and H-Treg patients; (c, d) individual changes in H-Treg (c) and in L-Treg (d) groups. (e) Changes (mean $\pm \mathrm{SEM}$ ) in C-peptide AUC in $\mathrm{H}$-Treg vs L-Treg patients. Data were normalised by baseline values for each patient at the different time points and are represented as fold change, but all statistics were calculated using the raw data

only one that maintained a significant increase of Tregs throughout the maintenance period. This dose is close to the $260,000 \mathrm{IU} / \mathrm{m}^{2}$ every 3 days proposed by others $[17,38,39]$.

We noticed a greater variability of the response in the high Treg responders (Fig. 3c), not previously seen in other patients treated with IL-2. It remains to be seen whether these peculiar responses to IL-2 are related to age or to the fact that we treated patients with recent-onset type 1 diabetes, which may correspond to a period of instability of the immune response. We also need to consider that fluctuations in proportions of Tregs in the circulation may also reflect recruitment to the pancreas or lymphoid tissues, or other tissues, which could be beneficial. Obviously, this hypothesis is not possible to test without access to tissue or advanced imaging to track Tregs.

Fig. 5 Biomarkers of Treg response to 1d-IL2. (a-e) Dotplot representations showing statistically significant correlations between the expression levels of soluble proteins and the percentage of Treg FoxP $3^{+}$ at day 5 relative to baseline in patients. (a) IL-22, (b) IL-27, (c) IL-28, (d) IL-2RA and (e) VEGFR2. The regression lines are indicated in blue and the confidence intervals are indicated with grey ribbons. The Spearman coefficients of correlation and the associated $p$ values are indicated for each cytokine. (f, g) Boxplot and jitter representations showing the expression levels for cytokines (IL-2RA and VEGFR2) found to be statistically different between the groups of low responders and high responders to ld-IL2 treatment. $p<0.05$, by the Wilcoxon rank-sum test. (h, i) Barplot and dotplot representations showing the estimated variable importance, quantified using the generalised cross-validation coefficient, and the prediction capacity of the regression model 

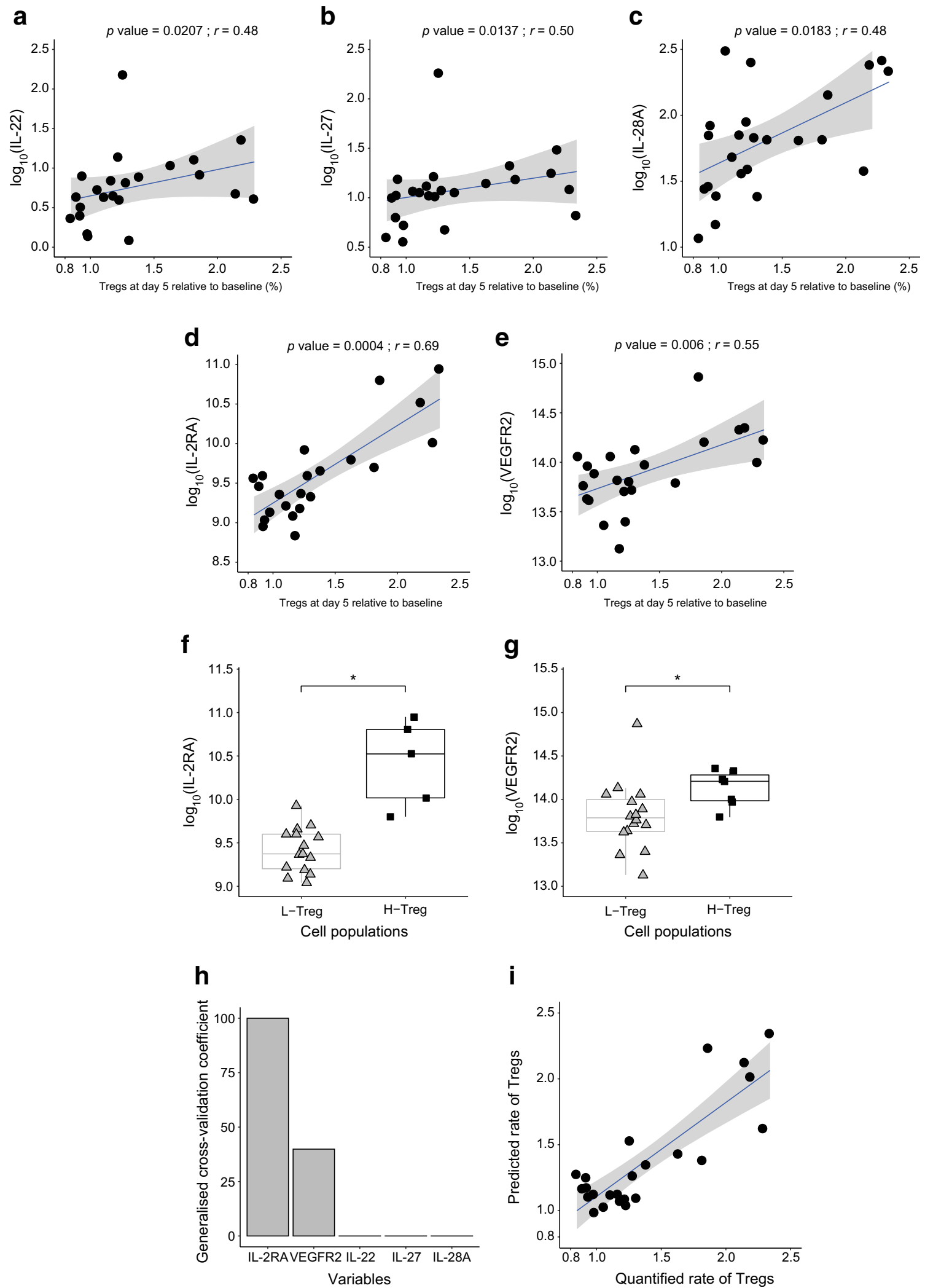

There were no noticeable differences in diabetes outcome in the different dose groups. All patients showed a decrease in C-peptide production over time, with a progressive decrease in the C-peptide AUC during an MMTT. However, when comparing the $\mathrm{H}$ - with the L-Treg responders, the former group showed a clear trend to improved preservation of 
stimulated insulin secretion, the decrease of stimulated Cpeptide from baseline being significant for L-Treg patients $(p<0.001)$, but not for H-Treg patients.

In most studies reporting some preservation of insulin secretion, after treatment there was a delay in C-peptide decline, but afterwards the treated and placebo groups had a similar slope for their C-peptide decline [40, 41]. We observed the contrary in this study: the C-peptide declined initially with the same slope in H-Treg and L-Treg patients, but after 6 months of follow-up the H-Treg group exhibited less decline in C-peptide, which continued to be higher until the end of the follow-up, about 3 months after the 1 year treatment. In addition, there was also a trend to less increase in fasting blood glucose levels in H- vs L-Treg responders (ESM Table 4). While these findings are exploratory, and concern a small number of patients and so are not statistically significant, they suggest that Treg regulation may require some time to show benefit. As therapies that debulk/deplete Teffs (cyclosporin [1, 4, 42], thymoglobulin [43], anti-CD3 [40], anti-memory T cell agents [43]) may allow early preservation of C-peptide, this suggests that combination with such agents could help maintain and enhance preservation of insulin secretion.

Overall, this study provides novel insights into the use of ld-IL2 therapy for type 1 diabetes (and beyond). First, it confirms the good safety profile over a 1 year treatment period in children. Second, it provides more data about individual responsiveness to ld-IL2 doses; the primary outcome at 5 days, as implemented in this trial, could be further investigated as a biomarker of response that could guide dose adjustment to uniformly achieve a $60 \%$ increase in Tregs. Future trials could validate this outcome as a biomarker for early prediction of responders to personalised dosing regimens. While the study was not formally powered to assess impact of the therapy on insulin secretion, the potential effects on preservation of insulin secretion in those with a higher Treg response provide an initial signal of clinical benefit that supports further investigation. We are currently completing enrolment of an ld-IL2 Phase IIb trial in Europe (Low-dose rhIL-2 in Patients With Recently-diagnosed Type 1 Diabetes [DIABIL-2], NCT02411253). In this trial, 138 patients with recently diagnosed type 1 diabetes, 6-35 years old, are being treated for 1 year with $1 \mathrm{MIU} /$ day for adults and $0.5 \mathrm{MIU} \mathrm{m}{ }^{-2}$ day $^{-1}$ of IL-2 with a maximum of $1 \mathrm{MIU} /$ day for children and adolescents, or placebo, according to two arms, in which IL-2 is given once a week or fortnightly during the maintenance period. This treatment scheme is fully supported by the current study.

We envisage that ld-IL2 could be beneficial not just at onset, but even later in patients with more established type 1 diabetes, a notion that will be tested in a planned trial (NCT03243058). Finally, the recent milestone results showing that it is possible to delay type 1 diabetes onset by a single injection of teplizumab [44] should also prompt the use of ld-
IL2 in disease prevention. The good safety profile of ld-IL2 and the fact that it does not induce anti-drug antibody should make it an excellent candidate for this indication, alone or after a first teplizumab injection.

Acknowledgements We thank the patients and the members of the DFChild study group for their participation. We thank all the personnel of the Clinical Investigation Center for Biotherapies (CIC-BTi), and in particular M. Barbié, C. Degbé, N. Féry, A. L. Raveu, F. Pitoiset and K. El Soufi for their excellent help, and of the Clinical Investigation Center of the Robert-Debré Hospital. We thank O. Tran for the monitoring of the study, G. Bensimon for his initial contribution to the trial design and A. Filleron and R. Cezar for help in Treg analyses at the Nîmes Hospital.

Data availability Individual participant data from this study (after deidentification) will be available from the publication date of this manuscript on a collaborative basis for individual participant data meta-analyses. Proposals should be directed to the corresponding author.

Funding This study was funded by Assistance Publique-Hôpitaux de Paris, Investissements d'Avenir programme (ANR-11-IDEX-0004-02, LabEx Transimmunom and ANR-16-RHUS-0001, RHU iMAP) and European Research Council Advanced Grant (FP7-IDEAS-ERC322856, TRiPoD).

Authors' relationships and activities $\mathrm{DK}, \mathrm{MR}$ and $\mathrm{CBe}$ are co-inventors of a patent entitled 'IL 2 based therapy' (OEB 11305269.0) and DK and MR are shareholders in ILTOO Pharma, the exclusive licensee of this patent.

Contribution statement $\mathrm{PB}, \mathrm{JCC}$, MP and T-AT were the principal clinical investigators of the study and participated in the acquisition of data at their study sites in the Paris area and Nîmes. RS, CBi, JB and CS were clinical investigators of the study and participated in the acquisition of data. RL, CA and AH contributed to data analyses. NT performed the analysis and modelling of cytokine/chemokine expression levels. MR supervised immunomonitoring and analysed results. AR and PC performed the immunomonitoring and analysed results. $\mathrm{CBe}$ participated in the study design. EV performed the statistical analyses and interpretation of the data. DK conceived the study, analysed the results and wrote the article. All authors edited the article and approved the final version. DK is the guarantor of this work.

\section{References}

1. Stiller CR, Dupre J, Gent M et al (1984) Effects of cyclosporine immunosuppression in insulin-dependent diabetes mellitus of recent onset. Science 223(4643):1362-1367

2. The Canadian-European Randomized Control Trial Group (1988) Cyclosporin-induced remission of IDDM after early intervention. Association of $1 \mathrm{yr}$ of cyclosporin treatment with enhanced insulin secretion. Diabetes 37(11):1574-1582

3. Sobel DO, Henzke A, Abbassi V (2010) Cyclosporin and methotrexate therapy induces remission in type 1 diabetes mellitus. Acta Diabetol 47(3):243-250. https://doi.org/10.1007/s00592-0100188-2

4. Bougneres PF, Carel JC, Castano L et al (1988) Factors associated with early remission of type I diabetes in children treated with cyclosporine. N Engl J Med 318:663-670. https://doi.org/10. 1056/NEJM198803173181103 
5. Staeva TP, Chatenoud L, Insel R, Atkinson MA (2013) Recent lessons learned from prevention and recent-onset type 1 diabetes immunotherapy trials. Diabetes 62(1):9-17. https://doi.org/10. 2337/db12-0562

6. Michels AW, Eisenbarth GS (2011) Immune intervention in type 1 diabetes. Semin Immunol 23(3):214-219. https://doi.org/10.1016/j. smim.2011.07.003

7. Wing K, Sakaguchi S (2010) Regulatory T cells exert checks and balances on self tolerance and autoimmunity. Nat Immunol 11(1): 7-13. https://doi.org/10.1038/ni.1818

8. Tang Q, Henriksen KJ, Bi M et al (2004) In vitro-expanded antigenspecific regulatory $\mathrm{T}$ cells suppress autoimmune diabetes. J Exp Med 199(11):1455-1465. https://doi.org/10.1084/jem.20040139

9. Akbarpour M, Goudy KS, Cantore A et al (2015) Insulin B chain 923 gene transfer to hepatocytes protects from type 1 diabetes by inducing Ag-specific FoxP3 ${ }^{+} \mathrm{T}_{\text {regs. }}$. Sci Transl Med 7(289): 289ra81. https://doi.org/10.1126/scitranslmed.aaa3032

10. Sharabi A, Tsokos MG, Ding Y, Malek TR, Klatzmann D, Tsokos GC (2018) Regulatory T cells in the treatment of disease. Nat Rev Drug Discov 17(11):823-844. https://doi.org/10.1038/nrd.2018. 148

11. Marek-Trzonkowska N, Mysliwiec M, Dobyszuk A et al (2012) Administration of $\mathrm{CD} 4^{+} \mathrm{CD} 25^{\text {high }} \mathrm{CD} 127^{-}$regulatory $\mathrm{T}$ cells preserves $\beta$-cell function in type 1 diabetes in children. Diabetes Care 35(9):1817-1820. https://doi.org/10.2337/dc12-0038

12. Hartemann A, Bensimon G, Payan CA et al (2013) Low-dose interleukin 2 in patients with type 1 diabetes: a phase $1 / 2$ randomised, double-blind, placebo-controlled trial. Lancet Diabetes Endocrinol 1(4):295-305. https://doi.org/10.1016/S2213-8587(13)70113-X

13. Rosenzwajg M, Churlaud G, Hartemann A, Klatzmann D (2014) Interleukin 2 in the pathogenesis and therapy of type 1 diabetes. Curr Diab Rep 14(12):553. https://doi.org/10.1007/s11892-0140553-6

14. Klatzmann D, Abbas AK (2015) The promise of low-dose interleukin-2 therapy for autoimmune and inflammatory diseases. Nat Rev Immunol 15(5):283-294. https://doi.org/10.1038/nri3823

15. Yu A, Snowhite I, Vendrame F et al (2015) Selective IL-2 responsiveness of regulatory $\mathrm{T}$ cells through multiple intrinsic mechanisms supports the use of low-dose IL-2 therapy in type 1 diabetes. Diabetes 64(6):2172-2183. https://doi.org/10.2337/db14-1322

16. Rosenzwajg M, Churlaud G, Mallone R et al (2015) Low-dose interleukin-2 fosters a dose-dependent regulatory $\mathrm{T}$ cell tuned milieu in T1D patients. J Autoimmun 58:48-58. https://doi.org/ 10.1016/j.jaut.2015.01.001

17. Seelig E, Howlett J, Porter L et al (2018) The DILfrequency study is an adaptive trial to identify optimal IL-2 dosing in patients with type 1 diabetes. JCI Insight 3(19):pii:99306. https://doi.org/10.1172/jci. insight.99306

18. Rosenberg SA (2014) IL-2: the first effective immunotherapy for human cancer. J Immunol Baltim Md 1950 192(12):5451-5458. https://doi.org/10.4049/jimmunol.1490019

19. Siegel JP, Puri RK (1991) Interleukin-2 toxicity. J Clin Oncol 9(4): 694-704

20. Saadoun D, Rosenzwajg M, Joly F et al (2011) Regulatory T-cell responses to low-dose interleukin-2 in $\mathrm{HCV}$-induced vasculitis. N Engl J Med 365(22):2067-2077. https://doi.org/10.1056/ NEJMoa1 105143

21. Long SA, Cerosaletti K, Bollyky PL et al (2010) Defects in IL-2R signaling contribute to diminished maintenance of FOXP3 expression in $\mathrm{CD} 4^{+} \mathrm{CD} 25^{+}$regulatory T-cells of type 1 diabetic subjects. Diabetes 59(2):407-415. https://doi.org/10.2337/db09-0694

22. Tang Q, Adams JY, Penaranda C et al (2008) Central role of defective interleukin-2 production in the triggering of islet autoimmune destruction. Immunity 28(5):687-697. https://doi.org/10.1016/j. immuni.2008.03.016
23. Rabinovitch A, Suarez-Pinzon WL, Shapiro AM, Rajotte RV, Power R (2002) Combination therapy with sirolimus and interleukin-2 prevents spontaneous and recurrent autoimmune diabetes in NOD mice. Diabetes 51:638-645

24. Long SA, Rieck M, Sanda S et al (2012) Rapamycin/IL-2 combination therapy in patients with type 1 diabetes augments Tregs yet transiently impairs $\beta$-cell function. Diabetes 61(9):2340-2348. https://doi.org/10.2337/db12-0049

25. Baeyens A, Perol L, Fourcade G et al (2013) Limitations of IL-2 and rapamycin in immunotherapy of type 1 diabetes. Diabetes 62(9):3120-3131. https://doi.org/10.2337/db13-0214

26. Mayer-Davis EJ, Lawrence JM, Dabelea D et al (2017) Incidence trends of type 1 and type 2 diabetes among youths, 2002-2012. N Engl J Med 376(15):1419-1429. https://doi.org/10.1056/ NEJMoa1610187

27. Rosenzwajg M, Lorenzon R, Cacoub P et al (2019) Immunological and clinical effects of low-dose interleukin-2 across 11 autoimmune diseases in a single, open clinical trial. Ann Rheum Dis 78(2):209 217. https://doi.org/10.1136/annrheumdis-2018-214229

28. Aghaeepour N, Ganio EA, Mcilwain D et al (2017) An immune clock of human pregnancy. Sci Transl Med 2(15):eaan2946. https:// doi.org/10.1126/sciimmunol.aan2946

29. Noether GE (1987) Sample size determination for some common nonparametric tests. J Am Stat Assoc 82(398):645-647. https://doi. org/10.1080/01621459.1987.10478478

30. Friedman JH (1991) Multivariate adaptive regression splines. Ann Stat 19(1):1-67. https://doi.org/10.1214/aos/1176347963

31. Inshaw JRJ, Cutler AJ, Crouch DJM, Wicker LS, Todd JA (2020) Genetic variants predisposing most strongly to type 1 diabetes diagnosed under age 7 years lie near candidate genes that function in the immune system and in pancreatic $\beta$-cells. Diabetes Care 43(1): 169-177. https://doi.org/10.2337/dc19-0803

32. Paradowska-Gorycka A, Stypinska B, Pawlik A et al (2019) KDR (VEGFR2) genetic variants and serum levels in patients with rheumatoid arthritis. Biomolecules 9(8):355. https://doi.org/10.3390/ biom 9080355

33. Yang Z, Wang M, Yan T, Hu Z, Zhang H, Liu R (2019) Association between vascular endothelial growth factor receptor 2 rs11941492 C/T polymorphism and Chinese Han patients in rheumatoid arthritis. Medicine (Baltimore) 98(52):e18606. https:// doi.org/10.1097/MD.0000000000018606

34. Okamoto $\mathrm{M}$, Watanabe $\mathrm{M}$, Inoue $\mathrm{N}$, Ogawa $\mathrm{K}$, Hidaka $\mathrm{Y}$, Iwatani Y (2020) Gene polymorphisms of VEGF and VEGFR2 are associated with the severity of Hashimoto's disease and the intractability of graves' disease, respectively. Endocr J. https://doi.org/10.1507/ endocrj.EJ19-0480

35. Snarski E, Milczarczyk A, Franek E, Jedrzejczak W (2010) Potential role of immunoablation and hematopoietic cell transplantation in the treatment of early diabetes type 1 . Ann Transplant 15(3):75-79

36. Zorn E, Nelson EA, Mohseni M et al (2006) IL-2 regulates FOXP3 expression in human $\mathrm{CD} 4{ }^{+} \mathrm{CD} 25^{+}$regulatory $\mathrm{T}$ cells through a STAT-dependent mechanism and induces the expansion of these cells in vivo. Blood 108(5):1571-1579. https://doi.org/10.1182/ blood-2006-02-004747

37. Price-Troska T, Yang Z-Z, Diller D et al (2019) Inhibiting IL-2 signaling and the regulatory T-cell pathway using computationally designed peptides. Investig New Drugs 37(1):9-16. https://doi.org/ 10.1007/s10637-018-0606-9

38. Kennedy-Nasser AA, Ku S, Castillo-Caro P et al (2014) Ultra lowdose IL-2 for GVHD prophylaxis after allogeneic hematopoietic stem cell transplantation mediates expansion of regulatory $\mathrm{T}$ cells without diminishing antiviral and antileukemic activity. Clin Cancer Res 20(8):2215-2225. https://doi.org/10.1158/1078-0432. CCR-13-3205 
39. Todd JA, Evangelou M, Cutler AJ et al (2016) Regulatory T cell responses in participants with type 1 diabetes after a single dose of interleukin-2: a non-randomised, open label, adaptive dose-finding trial. PLoS Med 13(10):e1002139. https://doi.org/10.1371/journal. pmed.1002139

40. Chatenoud L, Bluestone JA (2007) CD3-specific antibodies: a portal to the treatment of autoimmunity. Nat Rev Immunol 7(8): 622-632. https://doi.org/10.1038/nri2134

41. Pescovitz MD, Greenbaum CJ, Bundy B et al (2014) B-lymphocyte depletion with rituximab and beta-cell function: two-year results. Diabetes Care 37(2):453-459. https://doi.org/10.2337/dc13-0626

42. Feutren G, Papoz L, Assan R et al (1986) Cyclosporin increases the rate and length of remissions in insulin-dependent diabetes of recent onset. Results of a multicentre double-blind trial. Lancet 2(8499): 119-124

43. Barlow AK, Like AA (1992) Anti-CD2 monoclonal antibodies prevent spontaneous and adoptive transfer of diabetes in the $\mathrm{BB} /$ Wor rat. Am J Pathol 141(5):1043-1051

44. Herold KC, Bundy BN, Long SA et al (2019) An anti-CD3 antibody, teplizumab, in relatives at risk for type 1 diabetes. N Engl J Med 381(7):603-613. https://doi.org/10.1056/NEJMoa1902226

Publisher's note Springer Nature remains neutral with regard to jurisdictional claims in published maps and institutional affiliations. 